\title{
Impact of hydrodynamics on seismic signals generated by iceberg collisions
}

\author{
Jason M. AMUNDSON, ${ }^{1}$ Justin C. BURTON, ${ }^{2}$ Sergio CORREA-LEGISOS ${ }^{3}$ \\ ${ }^{1}$ Department of Geophysical Sciences, University of Chicago, Chicago, IL, USA \\ E-mail: jason.amundson@uas.alaska.edu \\ ${ }^{2}$ Department of Physics, University of Chicago, Chicago, IL, USA \\ ${ }^{3}$ Departamento de Física, Universidad de Santiago de Chile, Estación Central, Santiago, Chile
}

\begin{abstract}
Full-glacier-thickness icebergs are frequently observed to capsize as they calve into the ocean. As they capsize they may collide with the glaciers' termini; previous studies have hypothesized that such collisions are the source of teleseismic 'glacial earthquakes'. We use laboratory-scale experiments, force-balance modeling and theoretical arguments to show that (1) the contact forces during these collisions are strongly influenced by hydrodynamic forces and (2) the associated glacial earthquake magnitudes (expressed as twice-integrated force histories) are related to the energy released by the capsizing icebergs plus a hydrodynamic term that is composed of drag forces and hydrodynamic pressure. Our experiments and first-order modeling efforts suggest that, due to hydrodynamic forces, both contact force and glacial earthquake magnitudes may not be directly proportional to the energy released by the capsizing icebergs (as might be expected). Most importantly, however, our results highlight the need to better understand the hydrodynamics of iceberg capsize prior to being able to accurately interpret seismic signals generated by iceberg collisions.
\end{abstract}

\section{INTRODUCTION}

Calving icebergs generate a rich spectrum of unique seismic signals (Qamar, 1988; O'Neel and others, 2007; Amundson and others, 2008; Richardson and others, 2010; Walter and others, 2010). These signals carry information about calving processes (e.g. ice fracture) and can be recorded in the far-field with excellent temporal resolution $\left(\mathrm{O}^{\prime} \mathrm{Neel}\right.$ and others, 2010). Unfortunately, a clear interpretation of calving-generated seismicity is lacking, thus limiting our ability to interpret these signals in terms of calving mass losses or physical processes.

Some calving events radiate long-period (35-150 s) teleseisms ('glacial earthquakes') that have very little energy at shorter periods, compared to tectonic earthquakes of similar magnitudes (Ekström and others, 2003, 2006; Amundson and others, 2008; Joughin and others, 2008; Nettles and others, 2008; Nettles and Ekström, 2010). The radiation patterns of glacial earthquakes are best modeled with shallow, horizontal single-force mechanisms acting at and pointing perpendicular to the glacier termini (Tsai and Ekström, 2007; Walter and others, in press); the earthquakes are typically reported in terms of a mass-displacement product that can be found by integrating the force history twice with respect to time. Using force-balance modeling, Tsai and others (2008) demonstrated that icebergs which collide with a glacier's terminus during calving events are capable of producing mass-displacement products that are consistent with seismic inversions. Since iceberg capsize appears to be strongly influenced by hydrodynamics (Burton and others, 2010), the resultant earthquake magnitudes from such collisions must also be affected by hydrodynamics.

We explore these hydrodynamic consequences by expanding on the laboratory-scale experiments of Burton and

\footnotetext{
*Present address: Department of Natural Sciences, University of Alaska Southeast, Juneau, AK, USA
}

others (2010), which use synthetic, plastic 'icebergs' to investigate iceberg capsize in the open ocean (i.e. away from bedrock or other obstacles). That initial study was designed to motivate and give guidance to more sophisticated modeling studies of calving processes, including seismo- and tsunamigenesis, mixing of stratified fjords, and ice-shelf collapse. In the present experiments, the icebergs were placed next to a plastic 'glacier terminus' and allowed to capsize, causing them to collide with the terminus. The evolution of the capsize events was determined with digital imaging and feature tracking. A simple iceberg-capsize model was then fitted to the data to estimate the contact force between the iceberg and the terminus. Finally, the resultant force histories were used, along with theoretical arguments, to investigate the potential impact that hydrodynamic forces may have on seismic signals generated by iceberg collisions.

\section{METHODS}

We constructed synthetic, box-shaped icebergs and a model terminus from low-density polyethylene plastic with density $\rho_{\mathrm{i}}=920 \mathrm{~kg} \mathrm{~m}^{-3}$. The icebergs had pre-capsize height $H=$ $10.3 \mathrm{~cm}$, across-glacier length $L=26.74 \mathrm{~cm}$ and various width-to-height aspect ratios, $\varepsilon$. The terminus had the same height and across-glacier length and was $15 \mathrm{~cm}$ long in the glacier flow direction (Fig. 1). The experiments were conducted in an acrylic aquarium tank with dimensions of $2.4 \mathrm{~m} \times 0.3 \mathrm{~m} \times 0.3 \mathrm{~m}$, which contained fresh water of density $\rho_{\mathrm{w}}=997 \mathrm{~kg} \mathrm{~m}^{-3}$ to a depth of $\sim 13 \mathrm{~cm}$.

The icebergs were hydrostatically placed next to the model terminus and were allowed to capsize 'top-out' or 'bottom-out' (counterclockwise and clockwise, respectively; see Fig. 1). The experiments were recorded with a digital video camera (Casio EX-FH20) at 30 frames per second. Iceberg rotation angle and center-of-mass coordinates were determined by tracking black dots placed on the icebergs' 

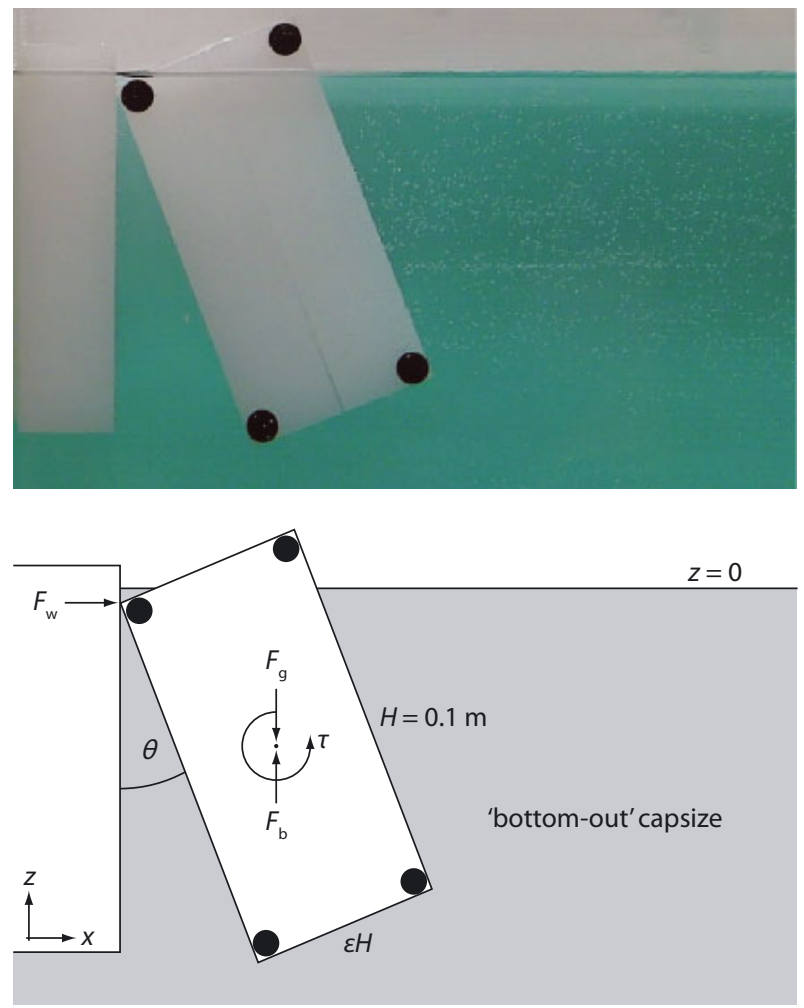

Fig. 1. Still-frame and schematic force balance (excluding the drag forces and torque) of the laboratory experiments, where $F_{\mathrm{g}}$ is the force due to gravity and $F_{\mathrm{b}}$ and $\tau$ are the force and torque due to buoyancy. All other variables are described in the text.

corners. Additionally, a small, closed-cell Styrofoam buoy was placed $20 \mathrm{~cm}$ from the wall to track waves produced by the capsize events. Due to its low density, the buoy was well coupled to the water surface.

Ignoring the effects of surface tension, the physical system investigated here can be described in terms of four dimensionless numbers: the iceberg aspect ratio; the density ratio between iceberg and water; the Froude number; and the Reynolds number. Of these, only the Reynolds number differs substantially from field observations. The Reynolds number in the experiments is $\sim 10^{4}$, or roughly five orders of magnitude lower than in the field. However, in both cases the Reynolds numbers are sufficiently high to indicate that turbulence can be expected to be an important dissipation mechanism. Consequently, the motion of a large iceberg $(H \sim 1 \mathrm{~km})$ may be well modeled using the results from our laboratory experiments. Additional details on dynamic and geometric similarity are presented by Burton and others (2010).

\section{RESULTS}

Our methods allow us to track the motion of a synthetic iceberg (Fig. 2) and to quantify its potential and kinetic energy (Fig. 3). Bottom-out capsize almost always occurred naturally in the experiments, i.e. it was the preferred capsize direction in the absence of any external perturbations. (Amundson and others (2010) explained similar field observations by invoking resistive forces from a proglacial ice melange.) We generally had to force top-out capsize, which could occur in nature when a terminus is undercut, by wedging the top of the iceberg away from the terminus.
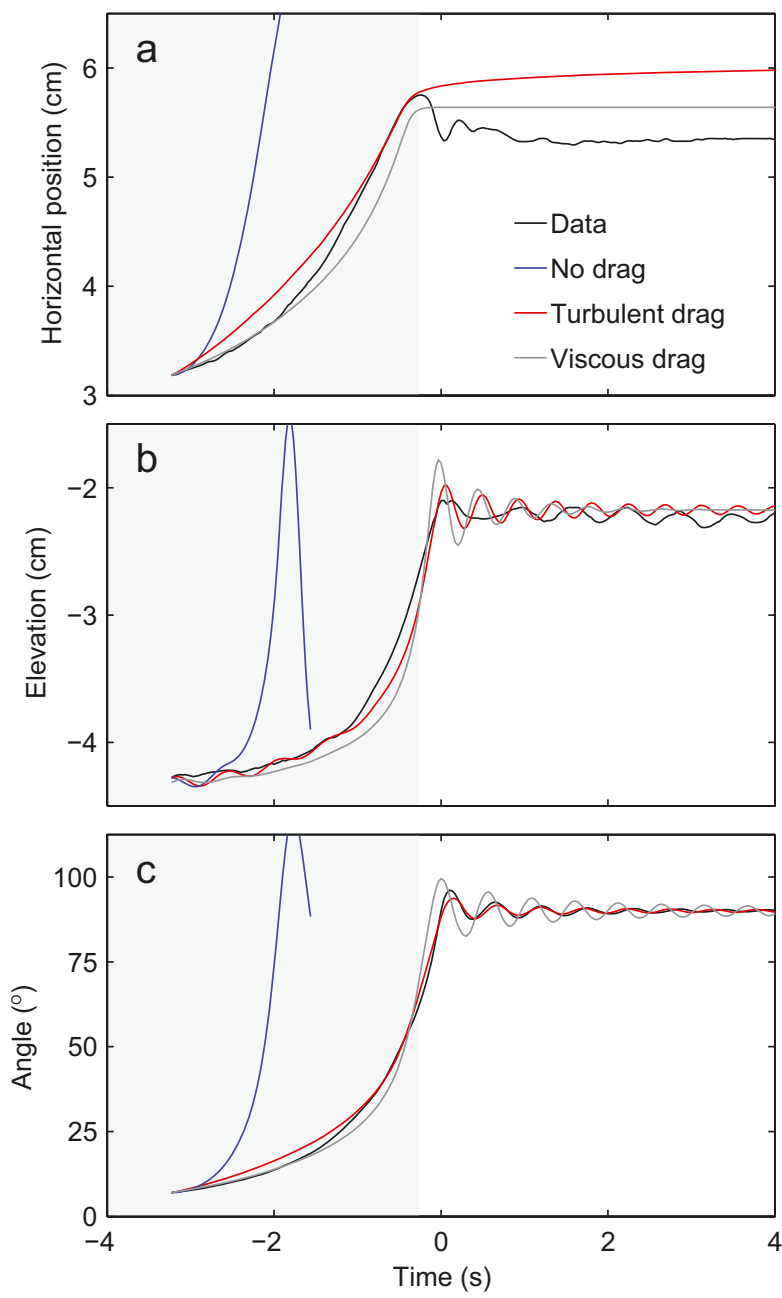

Fig. 2. (a) Horizontal position, (b) elevation and (c) rotation angle of an $\varepsilon=0.5$ iceberg as it calves and capsizes bottom-out. Black curves represent laboratory measurements. The time that the iceberg was in contact with the wall is indicated by the lightly shaded region. The blue, red and gray curves represent the results from a simple iceberg-capsize model (Section 4.1) using no drag, turbulent drag and viscous drag. The blue curve was truncated at an arbitrary time, as the iceberg oscillates indefinitely in the absence of hydrodynamic drag. The drag coefficients used in the red and gray curves were determined using a least-squares minimization. Best results were found using turbulent drag forces and torque, for which the drag coefficients were $\nu_{x}=2060 \pm 89.1 \mathrm{~kg} \mathrm{~m}^{-1}$, $\nu_{z}=155 \pm 77.1 \mathrm{~kg} \mathrm{~m}^{-1}$ and $\nu_{\theta}=0.01 \pm 0.0002 \mathrm{~kg} \mathrm{~m}^{2}$. The errors represent the $95 \%$ confidence intervals of the minimizations.

For both rotation directions and all aspect ratios used in this study, the maximum kinetic energy of the iceberg was significantly lower than the total potential energy released (Fig. 4). Furthermore the surface wave energy, not presented, amounted to less than a few percent of the energy released. This indicates that most of the potential energy is dissipated or transferred to the water, as also shown by Burton and others (2010).

We hypothesize that top-out capsize is strongly affected by the negative pressure gradient produced in the gap between the iceberg and the terminus, since water must flow in from the sides of the iceberg instead of from underneath, as is the case for bottom-out capsize. We further speculate that when an iceberg detaches from the wall during top-out capsize, water may eventually rush into the gap and propel 

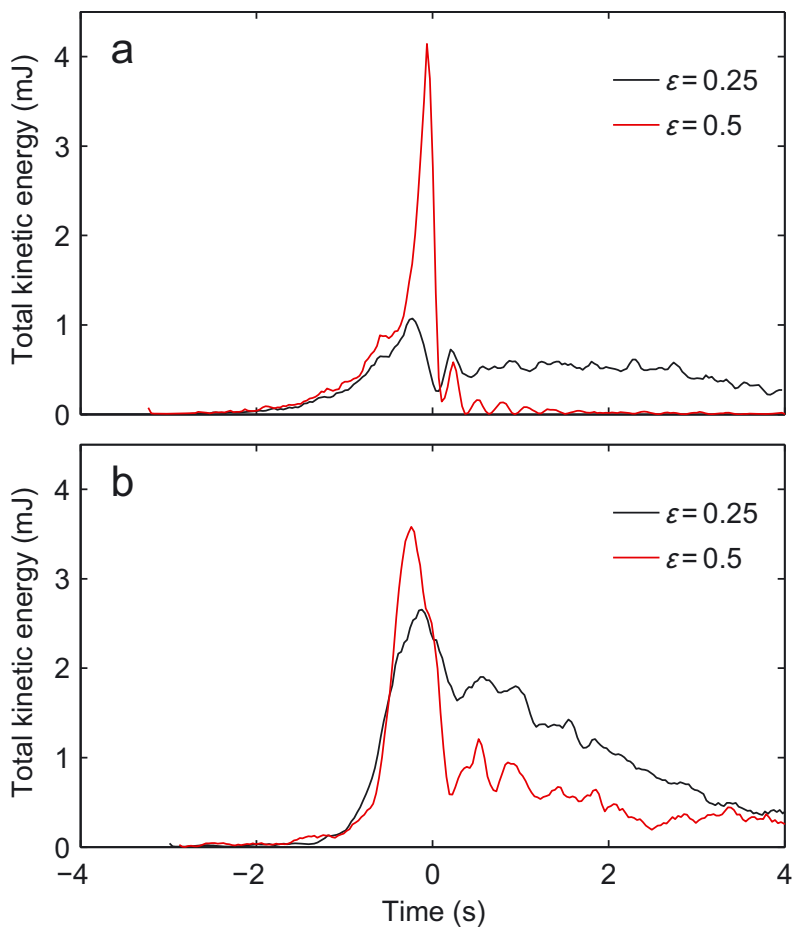

Fig. 3. Total (translational plus rotational) kinetic energy of synthetic icebergs that capsize (a) bottom-out and (b) top-out. The kinetic energy of thin icebergs (i.e. those with small $\varepsilon$ ) are most strongly influenced by hydrodynamic drag.

the iceberg horizontally (note the difference in translational kinetic energy between top-out and bottom-out capsize in Fig. 4b). This effect is strongest for thin icebergs with small aspect ratios.

\section{IMPLICATIONS FOR SEISMOGENESIS}

As a first step toward understanding how hydrodynamic forces may affect seismic signals generated by iceberg collisions, we now develop and apply an iceberg-capsize model to estimate the contact force between the iceberg and the glacier terminus. Due to the complexity of a complete, turbulent description of the hydrodynamics of iceberg capsize, we have modeled our experiments using hydrostatic forces and torques and simple bulk approximations to the drag forces and torque (Burton and others, 2010). In other words, the model ignores the details of the water's motion, which can cause rapidly varying pressure gradients, and thus the dynamics of top-out and bottom-out capsize are identical in the model. We also assume that the water level remains flat and stationary during capsize; an assumption that is supported by the small percentage of energy released as surface gravity waves. As we will show, our simple model is able to quantitatively capture the essential features that determine the iceberg's motion, including the icebergterminus contact force.

\subsection{Iceberg-capsize model}

The force and torque balances acting on an iceberg as it capsizes next to a glacier terminus (Fig. 1) are given by

$$
\begin{gathered}
\sum F_{X}=m \ddot{x}=F_{\mathrm{w}}-F_{\mathrm{d}}^{X}, \\
\sum F_{Z}=m \ddot{z}=-\frac{\partial U}{\partial z}-F_{\mathrm{d}}^{Z},
\end{gathered}
$$
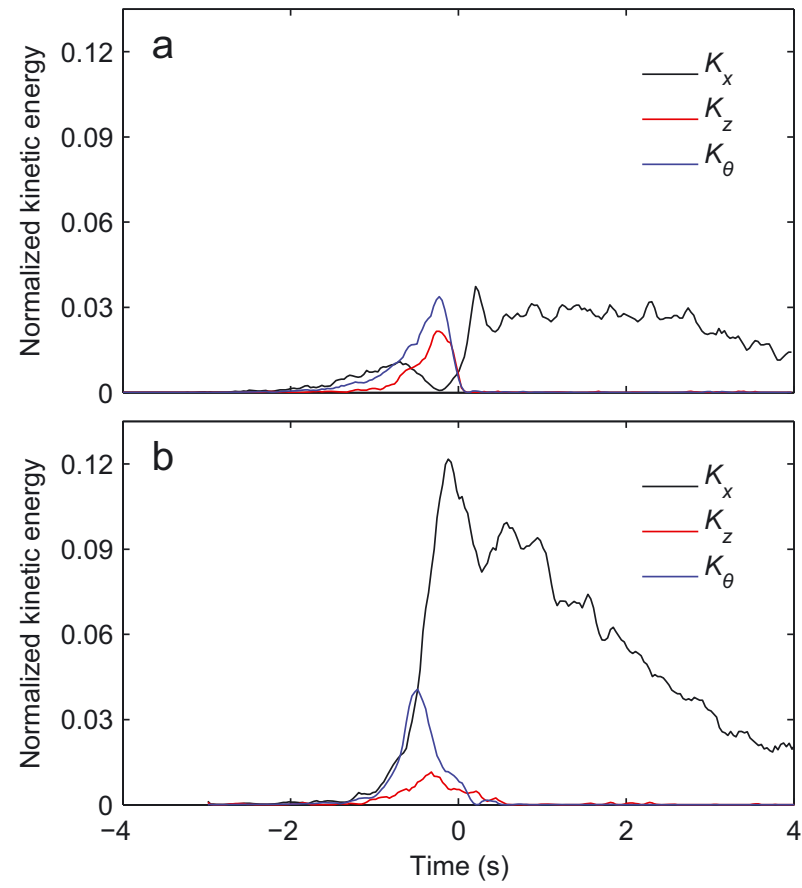

Fig. 4. Normalized horizontal, vertical and rotational kinetic energy of an $\varepsilon=0.25$ iceberg as it capsizes (a) bottom-out and (b) topout. The energies are normalized by the total gravitational potential energy released during the capsize event (Burton and others, 2010; MacAyeal and others, 2011) (see also Eqn (20)).

$$
\sum \tau=I \ddot{\theta}=-\frac{\partial U}{\partial \theta}-F_{\mathrm{w}} \frac{H}{2}(\cos \theta-\varepsilon \sin \theta)-\tau_{\mathrm{d}}
$$

where $x$ and $z$ are the horizontal and vertical coordinates of the center of mass, $\theta$ is the rotation angle (measured from vertical), double dots indicate the second time derivative, $m$ and $I$ are the mass and moment of inertia, $U$ is potential energy, $F_{\mathrm{w}}$ is the contact force against the wall, $H$ is the iceberg's initial height and $F_{\mathrm{d}}^{x}, F_{\mathrm{d}}^{z}$ and $\tau_{\mathrm{d}}$ are drag forces and drag torque. We have ignored friction between the iceberg and the glacier terminus, both to simplify this demonstration and because waveform modeling indicates that glacial earthquakes are generated by roughly horizontal single forces (Ekström and others, 2003, 2006; Tsai and Ekström, 2007; Walter and others, in press). Furthermore, model tests indicate that the addition of a frictional force has little bearing on the iceberg-capsize trajectory or force history. The same approximation was also made by Tsai and others (2008).

Equations (1-3) have four unknowns: $x, z, \theta$ and $F_{\mathrm{w}}$. An additional constraint is found by noting that, as long as the iceberg is in contact with the glacier terminus, $x$ and $\theta$ are geometrically related by

$$
x=\frac{H}{2}(\sin \theta+\varepsilon \cos \theta) .
$$

Once the iceberg loses contact with the wall, there is no force to accelerate the iceberg horizontally $\left(F_{\mathrm{w}} \rightarrow 0\right)$ and the velocity decays to zero as a result of drag.

The mass and moment of inertia of an idealized, boxshaped iceberg are

$$
m=\rho_{\mathrm{i}} \varepsilon H^{2} L
$$

and

$$
I=\frac{1}{12} \rho_{\mathrm{i}} \varepsilon H^{4} L\left(1+\varepsilon^{2}\right)
$$



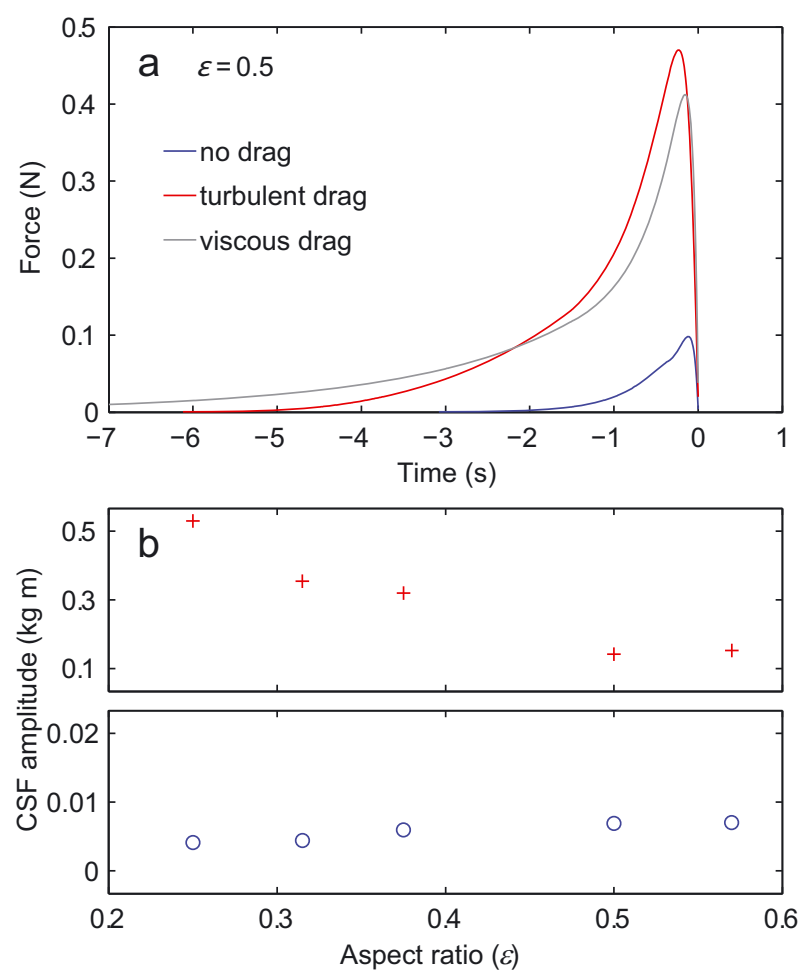

Fig. 5. (a) Contact force, $F_{\mathrm{W}}$, during the capsize of an $\varepsilon=0.5$, laboratory-scale iceberg. The blue, red and gray curves represent model results using no drag, turbulent drag and viscous drag, respectively. These curves correspond to the model runs shown in Figure 2. The time axis is set so that $t=0$ is the time that the iceberg loses contact with the terminus. (b) Centroid single force (CSF) amplitudes computed by integrating the contact force twice with respect to time for no drag (blue circles) and turbulent drag (red plus-signs). These CSF amplitudes ignore changes in back-force due to hydrodynamic drag.

where $\varepsilon H$ and $L$ are the iceberg's width (perpendicular to the axis of rotation) and length (parallel to the axis of rotation).

The potential energy of the iceberg, $U$, is computed by adding the potential energy of the submerged portion of the iceberg in a reduced-gravity environment to the potential energy of the subaerial portion of the iceberg. Details are given by Burton and others (2010).

The high Reynolds number associated with iceberg capsize suggests that energy dissipation occurs turbulently. Therefore, it is reasonable to assume that drag forces on the iceberg will be proportional to the square of the velocity (or angular velocity). In general, the drag force associated with the $i$ th coordinate $(i=x, z, \theta)$ depends on all velocities and the orientation of the iceberg, so that $F_{\mathrm{d}}^{i}=F_{\mathrm{d}}^{i}(\dot{x}, \dot{z}, \dot{\theta}, \theta)$ (see discussion of Brennen, 1982). This indicates that as the iceberg rotates, its direction of motion changes. Including all of the possible coordinate dependencies in the drag forces would greatly increase the model's complexity. We desire a minimal model that quantitatively agrees with laboratory data and has only a few adjustable parameters. For this reason we have also avoided any treatment of the 'added mass' tensor in our equations, which would introduce several more parameters (Brennen, 1982). A more accurate model that includes a hydrodynamic treatment with the NavierStokes equations will be the subject of future work.

We choose to approximate the drag forces and torque on the icebergs by assuming that

$$
F_{\mathrm{d}}^{x}=\nu_{x} \dot{x}^{2} \operatorname{sign}(\dot{x}),
$$

$$
\begin{gathered}
F_{\mathrm{d}}^{Z}=\nu_{z} \dot{z}^{2} \operatorname{sign}(\dot{z}), \\
\tau_{\mathrm{d}}=\nu_{\theta} \dot{\theta}^{2} \operatorname{sign}(\dot{\theta}),
\end{gathered}
$$

where $\nu_{x}, \nu_{z}$ and $\nu_{\theta}$ represent the drag coefficients (here assumed constant) and the dots indicate the first time derivative. In other words, we approximate the full drag force in the $x$-direction as (ignoring sign functions):

$$
\nu_{x} \dot{x}^{2} \approx \nu_{x}^{x} \dot{x}^{2}+\nu_{z}^{x} \dot{z}^{2}+\nu_{\theta}^{x} \dot{\theta}^{2} .
$$

(We have made similar approximations in the $z$ - and $\theta$ directions.) The simple drag coefficient that we solve for in the model, $\nu_{x}$, is therefore a function of the other drag terms and the translational and rotational velocities, so that

$$
\nu_{x} \approx \nu_{x}^{x}+\nu_{z}^{x}\left(\frac{\dot{z}}{\dot{x}}\right)^{2}+\nu_{\theta}^{x}\left(\frac{\dot{\theta}}{\dot{x}}\right)^{2} .
$$

The laboratory data indicate that during part of the capsize $(\dot{z} / \dot{x})^{2} \gg 1$ and that for the entire duration of the capsize $(\dot{\theta} / \dot{x})^{2} \gg 1$. This suggests that, unless $\nu_{z}^{x}$ and $\nu_{\theta}^{x}$ are very small, then $\nu_{x} \gg \nu_{x}^{x}$ and that $\nu_{x}$ should not be compared to a formulation involving a standard drag coefficient, $C_{\mathrm{d}}$. (For a body of cross section $A$ translating uniformly at velocity $v$ through a fluid of density $\rho_{\mathrm{w}}$, the drag force is $F_{\mathrm{d}}=$ $1 / 2 C_{\mathrm{d}} \rho_{\mathrm{w}} A v^{2}$, where $C_{\mathrm{d}} \approx 0.4-1.5$.)

The force and torque histories of the capsizing icebergs are found by solving Eqns (1-4), comparing the results to laboratory data and iteratively adjusting $\nu_{x}, \nu_{z}$ and $\nu_{\theta}$ to reduce the normalized root-mean-square error between the model output and the laboratory data. The results are shown in Figures 2 and 5a. The agreement between the data and the model is strikingly good, especially considering the level of hydrodynamic simplification in the model. The model indicates that including hydrodynamic drag can greatly increase both the duration and the magnitude of the icebergterminus contact force, $F_{\mathrm{w}}$. The former is not surprising given the form of Eqn (1), which indicates that drag forces can decrease the iceberg's acceleration and therefore increase the amount of time that the iceberg remains in contact with the terminus. The latter, which is less intuitive, arises because the horizontal velocity is tightly coupled to the rotation angle and angular velocity (Eqn (4)). As a result, the contact force is a highly complex, non-intuitive function that depends on all drag coefficients, positional coordinates and positional velocities.

The force against the terminus is a consequence of buoyancy-driven rotation. As the iceberg capsizes, it pushes the water out of the way and, consequently, the water pushes back against the iceberg and pins it against the terminus. When hydrodynamic drag is ignored, there is no additional reaction force from the water and the contact force is simply determined by solving Newton's equations with hydrostatic forces. An analogous example occurs when an iceberg capsizes within a pack of icebergs. Using static equilibrium arguments, MacAyeal and others (2003) demonstrate that the force exerted on adjacent icebergs during such capsize events can exceed the ice-shelf driving force by a factor of 10-100, where the ice-shelf driving force is given by (e.g. Thomas, 1973)

$$
F_{\mathrm{d}}=\frac{1}{2} \rho_{\mathrm{i}} g H^{2} L\left(1-\frac{\rho_{\mathrm{i}}}{\rho_{\mathrm{w}}}\right),
$$

where $g$ is acceleration due to gravity. For our laboratoryscale experiments, we find that $F_{\mathrm{d}} \sim 1 \mathrm{~N}$; thus, the force 
exerted on the wall by capsizing icebergs (in the absence of other icebergs) never exceeds half the ice-shelf driving force (Fig. 5).

We emphasize that Eqns (1-3) are generic and do not specify the dependencies of the drag forces. Our choice of turbulent drag forces that are quadratic in velocity and have simplified dependence on the coordinates and velocities is somewhat arbitrary. Given the Reynolds number for iceberg capsize, it seems the natural choice with the fewest parameters. As long as the model provides reasonable fits to the laboratory data, which it does, then the contact force histories, $F_{\mathrm{w}}(t)$, will be good approximations to the experiments. This is further supported by model tests using linear drag forces (i.e. the exponents in Eqns (7-9) are set to 1$)$, which produce similar iceberg trajectories and force histories, but with a somewhat higher root-mean-square error (Figs 2 and 5a).

\subsection{Glacial earthquake magnitudes}

Previous work has suggested that glacial earthquakes are generated when icebergs capsize and collide with a glacier's terminus (Amundson and others, 2008; Nettles and others, 2008; Tsai and others, 2008). The net (horizontal) force acting on the terminus during these events is

$$
F_{\text {net }}=F_{\mathrm{w}}-\Delta F_{\mathrm{p}},
$$

where $\Delta F_{\mathrm{p}}>0$ is the reduction in back-force arising from a decrease in water pressure in the void behind the iceberg. We can estimate the contact force using our laboratory data and simple numerical model; unfortunately, we currently do not have a convenient means for estimating $\Delta F_{\mathrm{p}}$.

The mass-displacement product of the collision, which we refer to as the centroid single force (CSF) amplitude for lack of a better term and to maintain consistency with previous studies, is found by integrating Eqn (13) twice with respect to time:

$$
\mathrm{CSF}=\int_{0}^{T} \int_{0}^{t} F_{\mathrm{w}} \mathrm{d} t^{\prime} \mathrm{d} t-\int_{0}^{T} \int_{0}^{t} \Delta F_{\mathrm{p}} \mathrm{d} t^{\prime} \mathrm{d} t,
$$

where $T$ is the time at which the iceberg loses contact with the terminus. Thus the CSF amplitude is a consequence of contact forces and hydrodynamic pressure. Equation (14) can be reduced to a single integral by combining the double integrals into one, changing the order of integration and evaluating the inner integral, which yields

$$
\mathrm{CSF}=\int_{0}^{T}\left(F_{\mathrm{w}}-\Delta F_{\mathrm{p}}\right)(T-t) \mathrm{d} t
$$

Rearranging Eqn (1) and inserting the result into Eqn (15) gives

$$
\mathrm{CSF}=\int_{0}^{T}\left(m \ddot{x}+F_{\mathrm{d}}^{x}-\Delta F_{\mathrm{p}}\right)(T-t) \mathrm{d} t .
$$

Since $\ddot{x}(0) \approx 0$ and $\dot{x}(0) \approx 0$, Eqn (16) simplifies to

$$
\mathrm{CSF}=m \Delta x+\int_{0}^{T}\left(F_{\mathrm{d}}^{x}-\Delta F_{\mathrm{p}}\right)(T-t) \mathrm{d} t,
$$

where $\Delta x$ is the horizontal distance that the iceberg's center of mass has moved between $t=0$ and $t=T$.

The initial horizontal position of the iceberg, relative to the glacier terminus, is simply $\varepsilon H / 2$. From inspection of Figure 1, we find that the position of the iceberg at the time when it loses contact with the glacier terminus cannot exceed $(H / 2) \sqrt{1+\varepsilon^{2}}$. Thus, the change in the iceberg's center of mass during the time that the iceberg is in contact with the terminus is given by

$$
\Delta x \leq \frac{H}{2}\left(\sqrt{1+\varepsilon^{2}}-\varepsilon\right) .
$$

Equation (18) becomes an equality when the drag coefficients are large, which we have verified with our icebergcapsize model (Section 4.1). The best-fit drag coefficients determined from our laboratory experiments, as well as videos of the experiments, indicate that Eqn (18) can be treated as an equality.

Thus, inserting Eqns (5) and (18) into Eqn (17) gives

$\mathrm{CSF}=\frac{1}{2} \rho_{\mathrm{i}} \varepsilon\left(\sqrt{1+\varepsilon^{2}}-\varepsilon\right) H^{3} L+\int_{0}^{T}\left(F_{\mathrm{d}}^{X}-\Delta F_{\mathrm{p}}\right)(T-t) \mathrm{d} t$.

The first term in Eqn (19), which is solely a consequence of iceberg geometry, scales approximately as $\varepsilon(1-\varepsilon)$ when $\varepsilon<0.5$. This is not too surprising, given that the total potential energy released by a capsizing iceberg, $E_{\text {cap, }}$ (see Burton and others, 2010; MacAyeal and others, 2011) also scales with $\varepsilon(1-\varepsilon)$ :

$$
E_{\text {cap }}=\frac{1}{2} \rho_{\mathrm{i}}\left(1-\frac{\rho_{\mathrm{i}}}{\rho_{\mathrm{w}}}\right) g \varepsilon(1-\varepsilon) H^{3} L .
$$

The CSF amplitude is therefore related to the total energy released during capsize. Rearranging Eqn (20) and inserting it into Eqn (19), we obtain

$\mathrm{CSF}=\frac{\sqrt{1+\varepsilon^{2}}-\varepsilon}{g(1-\varepsilon)} \frac{\rho_{\mathrm{w}}}{\rho_{\mathrm{w}}-\rho_{\mathrm{i}}} E_{\mathrm{cap}}+\int_{0}^{T}\left(F_{\mathrm{d}}^{X}-\Delta F_{\mathrm{w}}\right)(T-t) \mathrm{d} t$.

Noting that $\sqrt{\left(1+\varepsilon^{2}\right)}-\varepsilon \approx 1-\varepsilon$, Eqn (21) can be further simplified to

$$
\mathrm{CSF} \approx E_{\text {cap }} \cdot 1 \frac{\mathrm{s}^{2}}{\mathrm{~m}}+\int_{0}^{T}\left(F_{\mathrm{d}}^{x}-\Delta F_{\mathrm{p}}\right)(T-t) \mathrm{d} t .
$$

Equation (22) indicates that the CSF amplitude can be viewed as a sum of a 'geometric term' and a 'hydrodynamic term'. When hydrodynamic forces are ignored, the CSF amplitude is directly proportional to the total energy released during the calving event. However, our laboratory work indicates that drag forces (and presumably hydrodynamic pressures) can be large and highly variable during iceberg-capsize events.

As a demonstration of the potential impact that hydrodynamic forces can have on glacial earthquake magnitudes, in Figure 5b we plot the CSF amplitudes from the laboratoryscale experiments with (1) no hydrodynamic forces and (2) hydrodynamic drag but not hydrodynamic pressure. The latter can be taken as an upper bound on the role of hydrodynamic forces because hydrodynamic pressure will tend to offset the effect of drag forces (Eqn (22)). Figure 5b shows that the geometric term is proportional to iceberg aspect ratio. The drag term (case 2), however, is inversely proportional to aspect ratio and several times larger than the magnitude of the geometric term. This is because thin icebergs, which release less potential energy (Burton and others, 2010; MacAyeal and others, 2011; Eqn (20)), are more strongly affected by hydrodynamics than are wide icebergs. The net result is that when hydrodynamic pressure is neglected, the drag term dominates the CSF amplitude. Although our model lacks a full hydrodynamic description and is unable to account for hydrodynamic pressure, it does suggest that the CSF amplitude is strongly influenced by hydrodynamic forces and does not scale with iceberg geometry in a simple way. 

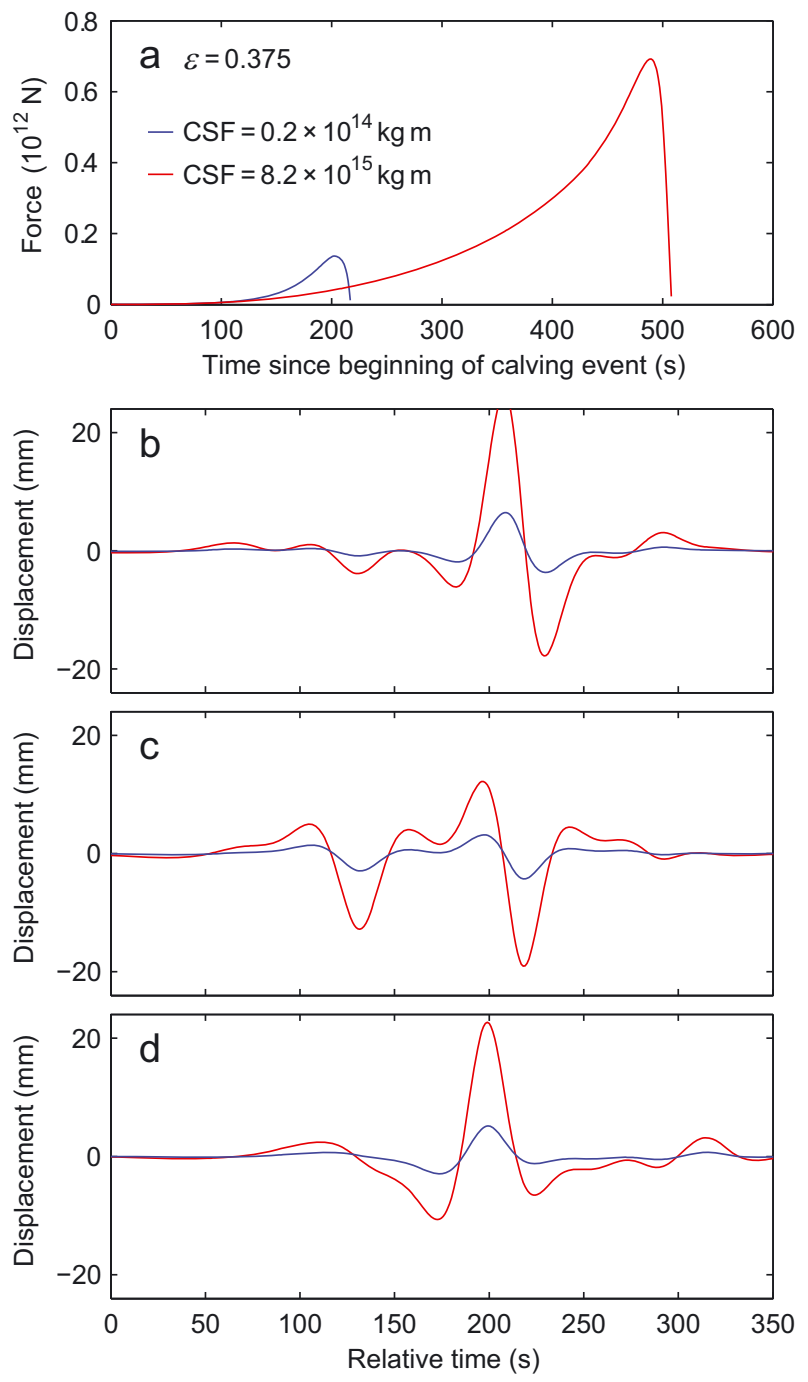

Fig. 6. (a) Synthetic contact forces, $F_{\mathrm{W}}$, generated during an iceberg-terminus collision involving a large iceberg $(H=1 \mathrm{~km})$. (b-d) Vertical (b), radial (c) and transverse (d) ground motion (seismograms) predicted for a site located $60 \mathrm{~km}$ from the glacier terminus. These synthetic seismic signals do not take into account the effect that hydrodynamic forces have on the net force (Eqn (13)). In all panels, the blue and red curves are the model results using no drag and turbulent drag, respectively.

\subsection{Seismic signal characteristics}

As a further demonstration of how hydrodynamic forces may influence seismic signals generated by iceberg collisions, we scaled up the force histories shown in Figure $5 \mathrm{a}$ and used the results to generate synthetic glacial earthquakes. The upscaling was done by non-dimensionalizing Eqns (1-3); i.e. by dividing mass scales by the iceberg mass, $m$ (Eqn (5)), length scales by the iceberg height, $H$, and timescales by a characteristic time, $T=H / V$, where $V$ is a characteristic velocity. The characteristic velocity was defined using the total energy released during the event, $E_{\text {cap }}$ (Eqn 20), so $V=\sqrt{2 E_{\text {cap }} / m}$. The up-scaled force histories are therefore found by multiplying the forces by $\left(H_{\text {field }} / H_{\text {lab }}\right)^{3}$ and the time by $\sqrt{H_{\text {field }} / H_{\text {lab }}}$. We set $H_{\text {field }}=1000 \mathrm{~m}$ to be roughly consistent with observations from Jakobshavn Isbræ, Greenland (Amundson and others, 2008) (Fig. 6a).

To compute the synthetic glacial earthquakes, we first constructed the theoretical elastic response of the
Earth to a horizontal delta impulse function (Green's function). The Green's functions were computed using fk3.0 (http://www.eas.slu.edu/People/LZhu/downloads/fk3.0.tar), which uses the propagator matrix approach developed by Zhu and Rivera (2002). Since we are not trying to model observed seismograms, we choose to use the default crust model given in $\mathrm{fk3}$.0. We assumed a shallow source with a depth of $0.1 \mathrm{~km}$, and calculated the response at a station located $60 \mathrm{~km}$ from the source. The source-station direction was parallel to $F_{\mathrm{w}}$.

The three Green's functions (vertical, radial and transverse) were then convolved with the synthetic force histories and filtered between 35 and $150 \mathrm{~s}$. Similar methods were also used by Walter and others (in press). We find that including drag forces in the iceberg-capsize model, but ignoring the transient force from hydrodynamic pressure, increases the amplitudes of the seismograms by about a factor of five but has little effect on the frequency content or shape of the seismograms (Fig. 6). This illustrates some of the difficulty of interpreting glacial earthquake signals in terms of glaciological processes.

\section{DISCUSSION AND CONCLUSIONS}

We have used laboratory-scale experiments to investigate the dynamics of full-glacier-thickness icebergs that capsize while calving. Our experiments indicate that most of the gravitational potential energy released by the icebergs is immediately transferred to the proglacial water (see also Burton and others, 2010). In addition, bottom-out capsize is strongly preferred over top-out capsize, presumably because for topout capsize the void behind the iceberg must be filled with water from the sides and not from underneath. A resistive ice melange may further increase the tendency for icebergs to capsize bottom-out (Amundson and others, 2010).

Despite the hydrodynamic complexities associated with iceberg capsize, we find that a simple iceberg-capsize model that only accounts for turbulent drag forces is able to reproduce most of the salient features of iceberg capsize adjacent to a glacier's terminus. The model indicates that hydrodynamic forces may greatly increase the magnitude of iceberg-terminus contact force and may cause thin icebergs to exert larger forces on the terminus than wider icebergs that release more potential energy. As a result, hydrodynamic forces may strongly influence the magnitude of seismic signals generated by iceberg-terminus collisions (i.e. glacial earthquakes).

A primary consequence of this study is that the hydrodynamics of iceberg capsize must be understood in greater detail prior to being able to confidently interpret (some) calving-generated seismic signals in terms of calving mass losses. Further advances in this topic will require more sophisticated laboratory experiments and numerical modeling exercises that aim to, for example, quantify hydrodynamic pressure gradients, account for non-uniform water densities and explore capsize dynamics of icebergs that have morerealistic geometries.

\section{ACKNOWLEDGEMENTS}

Funding for this project was provided by the US National Science Foundation (NSF) Antarctic Sciences Program (ANT0944193) and Materials World Network (DMR0807012). We thank D.S. Abbot, L.M. Cathles IV, K.N. Darnell, N. Guttenberg, D.R. MacAyeal and 
W.W. Zhang for discussions that inspired this work, and F. Walter for help with waveform modeling. This paper greatly benefited from the comments of D. Benn, an anonymous reviewer and editor P. Christoffersen.

\section{REFERENCES}

Amundson JM, Truffer M, Lüthi MP, Fahnestock $M$, West $M$ and Motyka RJ (2008) Glacier, fjord, and seismic response to recent large calving events, Jakobshavn Isbræ, Greenland. Geophys. Res. Lett., 35(22), L22501 (doi: 10.1029/2008GL035281)

Amundson JM, Fahnestock M, Truffer M, Brown J, Lüthi MP and Motyka RJ (2010) Ice melange dynamics and implications for terminus stability, Jakobshavn Isbræ, Greenland. J. Geophys. Res., 115(F1), F01005 (doi: 10.1029/2009JF001405)

Brennen CE (1982) A review of added mass and fluid inertial forces. US Department of the Navy, Port Hueneme, CA (Tech. Rep. CR82.010)

Burton JC and 9 others (2010) Laboratory investigations of iceberg-capsize dynamics, energy dissipation and tsunamigenesis. J. Geophys. Res., 117(F1), F01009 (doi: 10.1029/ 2011JF002089)

Ekström G, Nettles M and Abers GA (2003) Glacial earthquakes. Science, 302(5645), 622-624 (doi: 10.1126/science. 1088057)

Ekström, G, Nettles M and Tsai VC (2006) Seasonality and increasing frequency of Greenland glacial earthquakes. Science, 311(5768), 1756-1758 (doi: 10.1126/science.1122112)

Joughin I and 8 others (2008) Ice-front variation and tidewater behavior on Helheim and Kangerdlugssuaq Glaciers, Greenland. J. Geophys. Res., 113(F1), F01004 (doi: 10.1029/2007JF000837)

MacAyeal DR, Scambos TA, Hulbe CL and Fahnestock MA (2003) Catastrophic ice-shelf break-up by an ice-shelffragment-capsize mechanism. J. Glaciol., 49(164), 22-36 (doi: 10.3189/172756503781830863)

MacAyeal DR, Abbot DS and Sergienko OV (2011) Icebergcapsize tsunamigenesis. Ann. Glaciol., 52(58), 51-56 (doi: $10.3189 / 172756411797252103)$
Nettles M and Ekström G (2010) Glacial earthquakes in Greenland and Antarctica. Annu. Rev. Earth Planet. Sci., 38, 467-491 (doi: 10.1146/annurev-earth-040809-152414)

Nettles M and 12 others (2008) Step-wise changes in glacier flow speed coincide with calving and glacial earthquakes at Helheim Glacier, Greenland. Geophys. Res. Lett., 35(24), L24503 (doi: 10.1029/2008GL036127)

O'Neel S, Marshall HP, McNamara DE and Pfeffer WT (2007) Seismic detection and analysis of icequakes at Columbia Glacier, Alaska. J. Geophys. Res., 112(F3), F03S23 (doi: 10.1029/2006JF000595)

O'Neel S, Larsen CF, Rupert N and Hansen R (2010) Iceberg calving as a primary source of regional-scale glacier-generated seismicity in the St Elias Mountains, Alaska. J. Geophys. Res., 115(F4), F04034 (doi: 10.1029/2009JF001598)

Qamar A (1988) Calving icebergs: a source of low-frequency seismic signals from Columbia Glacier, Alaska. J. Geophys. Res., 93(B6), 6615-6623 (doi: 10.1029/JB093iB06p06615)

Richardson JP, Waite GP, FitzGerald KA and Pennington WD (2010) Characteristics of seismic and acoustic signals produced by calving, Bering Glacier, Alaska. Geophys. Res. Lett., 37(3), L03503 (doi: 10.1029/2009GL041113)

Thomas RH (1973) The creep of ice shelves: theory. J. Glaciol., 12(64), 45-53

Tsai VC and Ekström G (2007) Analysis of glacial earthquakes. J. Geophys. Res., 112(F3), F03522 (doi: 10.1029/2006JF000596)

Tsai VC, Rice JR and Fahnestock M (2008) Possible mechanisms for glacial earthquakes. J. Geophys. Res., 113(F3), F03014 (doi: 10.1029/2007JF000944)

Walter F, O'Neel S, McNamara DE, Pfeffer T, Bassis J and Fricker HA (2010) Iceberg calving during transition from grounded to floating ice: Columbia Glacier, Alaska. Geophys. Res. Lett., 37(15), L15501 (doi: 10.1029/2010GL043201)

Walter F, Amundson JM, $\mathrm{O}^{\prime}$ Neel S, Truffer $M$ and Fahnestock $M$ (in press) Analysis of low-frequency seismic signals generated during a multiple-iceberg calving event at Jakobshavn Isbræ, Greenland. J. Geophys. Res., (doi: 10.1029/2011JF002132)

Zhu L and Rivera LA (2002) A note on the dynamic and static displacements from a point source in multilayered media. Geophys. J. Int., 148(3), 619-627 (doi: 10.1046/j.1365-246X. 2002.01610.x) 